\title{
Critical Ingredients of Consumer Run Services: Results of a National Survey
}

\author{
Mark C. Holter, Ph.D. \\ Carol T. Mowbray, Ph.D. \\ Chyrell D. Bellamy, MSW \\ Peter MacFarlane, BA \\ Jean Dukarski
}

\begin{abstract}
Fidelity criteria are increasingly used in program monitoring and evaluation, but are difficult to derive for emerging models (i.e., those not based on theory or a research demonstration project). We describe steps used to develop and operationalize fidelity criteria for consumer-run (CR) mental health services: articulating and operationalizing criteria based on published literature, then revising and validating the criteria through expert judgments using a modified Delphi method. Respondents rated highest those structural and process components emphasizing the value of consumerism: consumer control, consumer choices and opportunities for decision-making, voluntary participation (and the absence of coercion), and respect for members by staff.
\end{abstract}

KEY WORDS: fidelity; consumer participation; empowerment; psychosocial rehabilitation; community mental health center; mental health services; program evaluation; self-help groups; United States.

\section{INTRODUCTION AND BACKGROUND}

Consumer involvement in mental health services planning and delivery dates back at least 50 years, as does literature on the benefits of consum-

Mark C. Holter, Carol T. Mowbray, Chyrell D. Bellamy, and Peter MacFarlane are affiliated with the University of Michigan School of Social Work, Ann Arbor.

Jean Dukarski is affiliated with the Justice in Mental Health Organization, Lansing, MI.

Address correspondence to Mark C. Holter, University of Michigan School of Social Work, 1080 South University Avenue, Ann Arbor, MI 48109-1106; e-mail: holter@umich.edu.

This research was supported through NIMH grant \#R24-MH51363-06, to the U-M School of Social Work, Center for Poverty, Risk and Mental Health. 
ers helping their peers (see Mowbray, Moxley, Jasper \& Howell, 1997). Consumer-run services are differentiated from self-help programs in being formally organized and funded for the purposes of providing services. This innovation is of recent origin but has been extolled for its benefits as an adjunct or alternative to professionally operated services. Policy and programmatic initiatives at state and federal levels have supported consumer involvement in service planning and provision; some have even recommended mandatory incorporation of consumerrun services in mental health systems (Van Tosh \& del Vecchio, 2000).

\section{Why Do We Care About Consumer-Run Services?}

Consumerism advocates contend that opportunities for individuals with serious mental illness to interact with their peers can impact psychological factors, like empowerment, self-efficacy, and hope, and so facilitate recovery (Yanos, Primavera \& Knight, 2001). According to several descriptive studies, consumers report high levels of satisfaction with consumer-run services (Mowbray \& Tan, 1992) as well as positive effects on life satisfaction (Chamberlin, Rogers \& Ellison, 1996). Segal, Silverman and Temkin (1993) laid out the processes through which these programs affect outcomes for people with mental disabilities, in contrast to traditional mental health services.

The literature on consumer run services (CRS) is expanding rapidly; according to one recognized mental health expert, "this model of community-based services... is an important new direction in community care" (Test, 1998, p. 429). However, there are few published research reports that provide any systematic overview of operations or outcomes in consumer-run services, with the exception of one cross-sectional study (Yanos et al., 2001) and one study which utilized an experimental design (Solomon \& Draine, 1996). Segal et al. (1993) concluded that even the basic practices of consumer-run agencies are poorly documented and poorly understood. In our budget-conscious, managed care-oriented, restricted economy, mental health services which are not validated face severe disadvantages in terms of expansion, or even maintenance of their funding base (Mead, Hilton \& Curtis, 2001). Thus, it appears that, without effectiveness research, consumer-run services are unlikely to move beyond the very limited funding they now receive (less than $1 \%$ of state mental health budgets; Mead et al., 2001).

Some current mainstream program models, like Assertive Community Treatment, have had the advantage of being based on a research demonstration project, from which the elements and operation of the model 
could be described and measured-serving as a check for further replications and for assessing the effectiveness of ACT variations in different contexts and with different target populations. Consumer-run services, unlike ACT, do not have any specifically identified prototype. The consumer-run service model has been primarily articulated in the writings of consumer-leaders and advocates. There are no program manuals to provide guidance to those wanting to replicate a CRS model, nor to researchers who must demonstrate that the program they are assessing really fits the criteria of being consumer-run. This is a serious disadvantage in conducting outcome studies, as well as in interpreting results.

\section{Why Critical Ingredients?}

Effectiveness research is now at the point of sophistication wherein blackbox outcome studies are no longer acceptable. Research requires that there be a model, which is based on a valid program theory, that valid and reliable criteria for fidelity to the model exist, that the criteria show discriminant validity (between the target model and other programs), and that the program being studied is assessed on these criteria. Furthermore, scientifically acceptable treatment effectiveness research should utilize a program manual for training and supervising intervention staff and for monitoring program quality and performance-thus helping to ensure fidelity to the model being researched.

While fidelity studies are relatively new to the mental health field, a growing number of programs have now developed fidelity criteria. The first program to do so was Assertive Community Treatment (ACT)—acknowledged as the most widely tested and successful model of community-based treatment and rehabilitation for adults with serious mental illness (Mueser et al., 1998). In ACT, the development of criteria and a program manual occurred more than a decade after the original efficacy study (Teague, Bond \& Drake, 1998). The first scale developed to assess fidelity to ACT principles followed the expert opinion method: a list of proposed critical ingredients was constructed from published descriptions of the model, and rated by ACT experts (academics and practitioners) (McGrew et al., 1994). Subsequent ACT fidelity studies have built on these criteria (Teague et al., 1995; McHugo et al., 1999).

Lucca (2000) produced a list of service components for a fidelity measure of clubhouse programs (a vocational rehabilitation model for adults with psychiatric disabilities) based on published literature, mission statements, and other documents from clubhouse programs. The checklist was innovative in that it included components that should and 
should not be part of the clubhouse model. Its weakness lay in being compiled by a single staff person.

Drake and colleagues (1996) developed a vocational rehabilitation program model for adults with psychiatric disabilities, Individual Placement and Support (IPS), through a federally-funded research project. The program produced significant positive findings in a randomized clinical trial. As part of the research, the authors produced fidelity criteria, a scale to measure fidelity, and a program manual (Bond et al., 1997).

Research on the effectiveness of consumer-run services is urgently needed to establish an evidence base for policy and advocacy. However, before service effectiveness research can meaningfully proceed a necessary step is to describe models of CRS and produce instrumentation to measure program fidelity. In this paper, we describe efforts to derive the critical program ingredients of the most common type of consumer run program - the consumer-run drop-in center (CRDI) - and the results of expert opinion surveys assessing the criteria.

\section{METHODS}

We reviewed published and unpublished literature produced by consumer-run organizations and advocacy groups on the activities, values, and goals of consumer drop-ins, and produced the following comprehensive description: Consumer-run drop-in centers play critical social support functions, especially for consumers with a history of and/or at high risk for psychiatric hospitalizations, providing organized and informal recreational and social activities where such individuals and the drop-in center staff can assist each other in solving their daily living problems (i.e., social, recreational, housing, transportation, and vocational). The major objectives of the drop-in are: (1) to provide a safe, supportive and normalizing environment in the community for individuals labeled "mentally ill," especially for those who are isolated in society, not participating in community mental health programs, or to whom even sheltered employment settings and other work-related activities are too stressful; (2) to provide an atmosphere of acceptance where individuals will feel needed and grow in self-worth, dignity and self-respect; (3) to increase knowledge about the community by learning from each other; (4) to provide a place where social and recreational activities can occur, enabling individuals with severe emotional difficulties to conquer social and communication problems and assume productive lifestyles in community settings; and (5) to help facilitate mental health consumers utilizing other human services and being integrated into their communities. Essential drop-in center activities include: having an appropriate and adequate space and location for the CRDI; providing immediate access for consumers during scheduled hours, which usually include weekends and/or evenings; utilizing mental health consumers as volunteers to assist with CRDI operations; providing a normalized environment through a variety of activities and resources; providing a monitoring network for individuals in crisis and those at high-risk for psychiatric hospitalization, allowing an opportunity for consumers using the drop-in to extend and receive assistance according to individual capabilities; providing positive role models 
and reinforcement so consumers can learn or relearn socially acceptable behaviors; acting as a liaison to community agencies; and allowing its participants to develop their own agenda based on the needs and interests of those being served. At a minimum, each CRDI provides social and recreational activities, informal counseling, assistance with transportation and other help needed to stay in the community, outreach, assistance with housing and vocational problems, and help with understanding and accessing needed human services including income maintenance.

The values of consumer-run drop-ins reflect a consumerism philosophy, which means, according to documents produced by the Justice in Mental Health Organization (JIMHO), a statewide consumer group in Michigan, "empowerment of peoplepeople who have experienced emotional and mental health problems and have been oppressed by society, enabled by professionals, and seen and believed to be 'less' than the rest of the population." Consumerism means ridding society of discrimination and prejudice-individuals who have or are experiencing emotional and mental health problems joining together in a movement to capture and/or regain their rights, their dignity, and their self-respect.

From this narrative description, we produced a preliminary listing of the essential ingredients of consumer-run drop-in centers. These proposed program criteria were grouped into domains for conceptual clarity, following Donabedian's (1980) classic framework. "Structure" in this framework refers to "the relatively stable characteristics of the providers of care, of the tools and resources they have at their disposal, and of the physical and organizational settings in which they work" (Donabedian, 1980, p. 81). "Process," the second major dimension described by Donabedian, refers to specific and observable activities in services and/or in methods of delivering those services. Because the process domain encompasses so many of the values and identified activities of drop-in centers, we utilized concepts developed by Maton and Salem (1995), on the characteristics of empowering community settings, to further categorize the process criteria. The Maton and Salem (1995) approach was chosen because writings of consumers frequently specify empowerment as an intended outcome of participation in consumer-run services. Thus, the process domain was subdivided into (a) belief systems, (b) opportunity role structure, and (c) social support. The following criteria resulted:

\section{Structure}

1. Consumer-run: All employees are consumers (Zinman, 1986; Segal, Silverman \& Temkin, 1993; Segal \& Silverman, 2002).

2. Consumer-controlled: Consumers constitute a majority of the Board and the Board makes all decisions about budget and operations (Zinman, 1986; Segal et al., 1993; Silverman, 1997; Segal \& Silverman, 2002).

3. Voluntary: Membership and participation are completely voluntary; there is no coercion from $\mathrm{CMH}$ or other mental health authorities to attend (Zinman, 1986; Segal et al., 1993; Chamberlain, Rogers \& Ellison, 1996; Segal \& Silverman, 2002).

4. Member determination: The membership or their elected leaders have the major voice in how their center is run, how decisions are made, and what policies are in place (rather than the director, the funding agency, or the mental health system) (Segal et al., 1993; Silverman, 1997; Segal \& Silverman, 2002).

5. Acceptability: The physical environment is acceptable and appropriate to the needs of consumers. The facility type and space allow the group to carry out member-determined services and activities. The CRDI is safe physically and emotionally, especially to vulnerable subgroups (women, racial/ethnic minori- 
ties, older adults), including its location, physical plant, and security (Chamberlain et al., 1996; Mead et al., 2001; Segal \& Silverman, 2002).

6. Accessibility: Consumers can get to the CRDI on their own or through arranged transportation; the Center is accessible to many users on foot or by public transportation (Chamberlain, et al., 1996).

7. Freedom from coercion: The center poses no threat of commitment, clinical diagnosis, or unwanted treatment. No one passes judgments by diagnosing, hospitalizing or medicating members (Segal et al., 1993; Silverman, 1997; Mead et al., 2001; Segal \& Silverman, 2002).

8. Respect: The center respects the diversity of participants (e.g., gender, age, race/ethnicity, religion, functional capacities) (LeDoux, 1997; Silverman, 1997).

9. The program is flexible and changes as members' needs evolve (LeDoux, 1997).

10. Facilitating referrals: The CRDI helps assure that members can access services and assistance from $\mathrm{CMH}$ and other human services (Chamberlain et al., 1996; Silverman, 1997).

11. Retention: The Center cares about its members; outreach and assistance are provided to regular members who fail to show up (Silverman, 1997).

12. Outreach: The Center cares about others in need of help; outreach and assistance are provided to locations (such as homeless shelters) where there may be individuals with mental illness in need (Silverman, 1997).

13. Activities and services available: are based on members' felt needs and probably differ for each center. They often include social and recreation activities; housing, transportation, informal counseling, vocational assistance, and help in getting basic needs met (Chamberlain et al., 1996; Silverman, 1997; Segal \& Silverman, 2002).

14. Availability: The Center's operation is stable and predictable. The Center is open to meet consumer needs; usually this means having evening and weekend hours and full availability during holidays like Christmas, Thanksgiving, etc. (Chamberlain et al., 1996).

15. Satisfaction: Members have ways to indicate dissatisfaction with aspects of their Center and to feel that they are heard (Teague et al., 1997; Segal \& Silverman, 2002).

\section{Process Belief Systems}

16. Empowerment: The Center encourages personal growth and development; and supports consumers' efforts to be themselves (Segal et al., 1993; Chamberlain et al., 1996; Silverman, 1997; Clark \& Krupa, 2002; Segal \& Silverman, 2002).

17. Recovery beliefs: The Center promotes the belief that recovery is possible and necessary in order for individuals to find meaning in their lives (LeDoux, 1997).

18. Recovery practices: In its philosophy and practices, each Center emphasizes responsibility for one's own health and behavior, taking control of one's life, not blaming others, focusing on individuals' strengths rather than deficits (Chamberlain et al., 1996; Segal \& Silverman, 2002).

19. Group empowerment: The center promotes development of "group consciousness" about the impact of societal structures and encourages consumers to exercise their individual and collective voices (Segal et al., 1993; Chamberlain et all, 1996; Mead et al., 2001; Segal \& Silverman, 2002).

20. Advocacy: The Center provides members the opportunity to develop individual and group advocacy skills related to relevant issues, such as changes in the mental health system, anti-stigma, entitlements, etc. (Segal et al., 1993; Chamberlain et al., 1996; Mead et al., 2001). 


\section{Process-Opportunity Role Structure}

21. Nonhierarchical relationships: Relationships with staff, Board members and other consumers at the Center foster acceptance. Hierarchies between staff and consumers do not exist (Zinman, 1986; Segal et al., 1993; LeDoux, 1997; Silverman, 1997; Clark \& Krupa, 2002; Segal \& Silverman, 2002).

22. Member activity: Members actively participate in operating the center (Segal et al., 1993; Chamberlain et al., 1996).

23. Member participation: Attendance levels are appropriate for the local population base; a high percentage of members regularly attend (Silverman, 1997).

24. Choices and decision-making opportunities: Members have choices presented to them and opportunities and encouragement to make decisions; from small decisions, such as when to come and leave and what to do at the Center; to larger decisions about Center operations and doing things for other members (Chamberlain et al., 1996; Silverman, 1997; Segal \& Silverman, 2002).

25. Practice and improve skills: Through participation and decision-making opportunities, members can improve skills in communication, interpersonal relationships, and concrete work-relevant areas (organizing and following through on an assignment, etc.) (Segal et al., 1993; Silverman, 1997; Segal \& Silverman, 2002).

26. Positive role modeling: Through a heterogeneous membership, consumers see individuals like themselves facing life's challenges; and experience role models of healthy behavior and social skills (Segal et al., 1993).

\section{Process—Social Support}

27. Reciprocity: Centers involve not just getting help, but also the opportunity and positive feelings engendered from giving help to peers (Chamberlain et al., 1996; Silverman, 1997; Mead et al., 2001; Segal \& Silverman, 2002).

28. Support: Friendships develop at the center; they provide joy and satisfaction, emotional support, understanding, concrete assistance; and promote learning from each other (Chamberlain et al., 1996; Silverman, 1997; Mead et al., 2001).

29. Sense of community: The CRDI provides a sense of family and belonging where people care about each other and work towards common goals (Segal et al., 1993; Mead et al., 2001).

30. Self-help: Members assist each other with self-management and problem solving skills (Silverman, 1997; Segal \& Silverman, 2002).

31. Awareness: Members are encouraged to improve individual and collective understanding by sharing life experiences (Segal et al., 1993; Mead et al., 2001).

Efforts to validate the criteria involved two waves of data collection with a panel of national consumerism experts, using a modified Delphi method.

\section{Participants}

National experts on consumer-run services $(\mathrm{N}=67)$ were identified through an extensive search of consumer newsletters (e.g., The Key), professional journal articles, and book chapters. Experts included consumers, advocates, service providers, and researchers, as well as individuals involved in a multi-site study of consumer operated services, funded by the Center for Mental Health Services. Respondents were from 21 states, representing all regions of the country. 


\section{Procedures}

In Wave I, experts were mailed a survey which asked them to indicate whether each criterion was critical to a consumer-run drop-in. Response categories included agree, disagree and neither. The survey also included an open-ended question to elicit additional criteria. Surveys were mailed, followed by email and telephone prompting messages two weeks later. Six surveys were returned due to insufficient forwarding addresses, and two individuals declined to participate because they did not consider themselves sufficiently expert. Twenty-nine surveys were received for a response rate of $47 \%$.

In Wave II, using the results of Wave I, a web-based survey was developed which included all 31 ingredients; one item was reworded for clarification. The items were randomly ordered, so as not to confound item ordering with domains. Completing the survey involved rank ordering the criteria statements in the following manner: Respondents were first asked to choose 10 items that were the most essential and 10 items that were the least essential to a consumer-run drop-in center (assigning a neutral value to the remaining 11 items). From the two lists of ten, respondents were then asked to choose four items from each list that were most essential and least essential. In this manner, items were given ratings as most essential (with a value of 2 ), essential (1), neutral (0), less essential (-1), and least essential (-2). This method was chosen to force respondents to distinguish critical ingredients from important but noncritical components of consumer-run programs. Respondents were also asked about their own characteristics: race/ethnicity, gender, educational level, years of experience $\mathrm{v} / \mathrm{v}$ consumer-run services, self-identification as consumer, as well as professional identification-e.g., researcher, clinical professional, etc. To insure that the instructions were clear, the survey was piloted with a sample of 12 staff and students having varying levels of Internet experience.

Postcards with instructions for accessing the web address of the survey were mailed to the 59 experts who comprised the Wave I survey sample. When respondents failed to complete the web-based survey within one month of the mailing, they were sent a paper/pencil version instead. Follow-up prompting procedures were the same as with Wave I. Eleven surveys were completed via the web and 13 with the paper version, for a total response rate of $40 \%$. All 24 respondents were white; 17 were female $(71 \%)$ and $8(33 \%)$ were self-reported mental health consumers. Most respondents chose more than one professional identification. Ten persons identified as researchers, 9 as clinical professionals, 9 as educators, and 2 as program administrators. Nineteen persons (79\%) identified as advocates. Respondents had reportedly worked in the area of consumer-run services for an average of 12.9 years. The respondents were from 14 states in each region of the country.

\section{RESULTS}

As expected, in Wave I, experts indicated that nearly all the criteria were essential to consumer-run services. The exceptions were, "All employees are consumers," "Hierarchies between staff and consumers do not exist," and "A high percentage of members regularly attend." The first two statements were also those that generated the most comments. Several respondents commented that only certain positions (like direct services staff vs. support staff or volunteers) should be filled 
exclusively by consumers. Other comments concerned hierarchiesthat they "should" not exist rather than that they "do" not exist. Other respondents wanted statements to be made more specific or elaborated on some of the criteria.

For Wave II data, preliminary analyses examined whether the answers varied by status of respondent (mental health consumer vs. non-consumer) or by years of experience. The number of significant differences was not greater than what could be expected by chance; consequently, the results are reported for the entire group of respondents. Results from the survey are presented in Table 1 . The criteria are arranged from high to low endorsement within each domain, and the domains are presented in order of importance as well. The description of each criterion includes a number denoting the order of the question on the actual survey.

\section{Structure}

Items within the structural domain were rated as most important by the respondents, with the voluntary nature of participation in CRDIs topping the list. Respondents gave high ratings to the absence of the threat of commitment, diagnosis, or unwanted treatment, and to respect for member diversity. Program governance variables were seen as essential criteria for CRDIs, as evidenced by endorsements for consumers constituting a majority of the board and for members having a way to voice dissatisfaction. Having activities and services that reflect the needs of consumers was also rated as important. The need for all employees to be consumers, stable and predictable operations, flexible programming that changes as members needs evolve, and members determining program operations were all ranked positively but not highly, while transportation issues were ranked as fairly neutral by respondents. Structural criteria ranked as least important were appropriateness of the physical environment, helping members to access services outside of the center, and outreach to existing members, or to new members.

\section{Belief System}

The set of criteria reflecting belief systems of the CRDI was the next highest ranked domain. The criteria seen as most important were promoting the belief that recovery is possible and personal responsibility for health and behavior within a strengths-based approach. Encourag- 
TABLE 1

Survey Results of Critical Ingredients of Consumer-Run Drop-In Programs (CRDIs)

Domain and Criteria

Mean $^{a} \quad S D$

Structure

Membership and participation is completely voluntary; there is no coercion from $\mathrm{CMH}$ or other mental health authorities to attend. (20)

$1.17 \quad 1.17$

The center poses no threat of commitment, clinical diagnosis or unwanted treatment to its members.

$0.92 \quad 1.10$

Consumers constitute a majority of the Board. (14)

$0.75 \quad 1.26$

The center respects the diversity of participants (gender, age, race/ethnicity, religion, sexual orientation and ability status). (10)

$0.50 \quad 1.14$

Activities and services are available that reflect members' needs, e.g., for social and recreational activities, housing, transportation and vocational assistance, informal counseling, help in getting basic needs met. (6)

Members have ways to indicate dissatisfaction and satisfaction with aspects of their center and feel that they are heard. (2)

Members determine program operations, how decisions are made and what policies are in place. (7)

The program is flexible and changes as members' needs evolve. (30)

The center's operation is stable and predictable. (12)

All employees are consumers. (16)

$0.17 \quad 0.92$

$0.13 \quad 1.26$

Consumers can get to the center on their own or through arranged transportation. (23)

$0.08 \quad 1.44$

The physical environment is acceptable and appropriate to the needs of the consumers. (18)

$0.04 \quad 1.08$

The center helps members to access services and assistance from other needed sources $(\mathrm{CMH}$ and other human services). (31)

$-0.50 \quad 1.06$

Outreach is provided to retain existing members. (25)

$-0.50 \quad 1.06$

The center does outreach to recruit new members at locations (such as homeless shelters) where there may be individuals in need. (17) 
TABLE 1 (continued)

Domain and Criteria

The center promotes the belief that recovery is possible and necessary for individuals to find meaning in their life. (5)

The center emphasizes responsibility for one's own health and behavior, focusing individuals on their strengths rather than deficits. (8)

The center encourages personal growth and development. (22)

The center provides members the opportunity to develop individual and group advocacy skills related to issues such as change in the mental health system, anti-stigma campaigns, entitlements, etc. (21)

The center promotes the process by which individuals come together and develop an awareness or "group consciousness" about the impact of societal structures and how they impact the group. (29)

Process-Opportunity Role Structure

Members have choices presented to them and opportunities to make decisions at the center. (3)

Members actively participate in operating the center. (26)

Hierarchies between staff and consumers do not exist. (1)

$-0.04 \quad 1.23$

Through participation and decision-making opportunities, members can improve skills in communication, interpersonal relationships, and other more concrete, work-relevant areas. (19)

Process-Social Support

Consumers serve as positive role models to other consumers. (9)

The center provides a sense of belonging, a sense of family where people care about each other, and are working towards common goals. (27)

Friendships developed at the center provide satisfying relationships and emotional support. (11) 
TABLE 1 (continued)

\begin{tabular}{|c|c|c|}
\hline Domain and Criteria & $\operatorname{Mean}^{a}$ & $S D$ \\
\hline $\begin{array}{l}\text { Consumers experience the opportunity for and the } \\
\text { positive feelings engendered from giving help to } \\
\text { peers. (4) }\end{array}$ & 0.04 & 1.20 \\
\hline $\begin{array}{l}\text { Members assist each other with self-management } \\
\text { and problem solving skills. (24) }\end{array}$ & -0.08 & 0.88 \\
\hline $\begin{array}{l}\text { Members are encouraged to improve individual and } \\
\text { collective understanding by sharing life experi- } \\
\text { ences. ( } 28)\end{array}$ & -0.38 & 0.97 \\
\hline
\end{tabular}

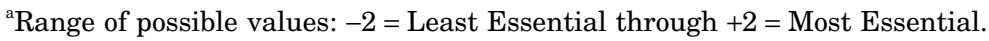

Note: Numbers in parenthesis indicate the order in which criteria were presented in the survey.

ing personal growth and development was rated positive, but lower, whereas providing an opportunity to develop individual and group advocacy skills and promoting group consciousness were rated as the least important survey items from any domain.

\section{Opportunity Role Structure}

Respondents felt it was important that members have choices presented to them, and opportunities to make decisions. The absence of hierarchy between staff and consumers and active participation by members received essentially neutral ratings. Improvement of social skills through center participation was seen as less important, as was regular attendance.

\section{Social Support}

Social support was rated as the least critical domain. Its highest ranked criteria was that the center provides a sense of belonging and that consumers serve as positive role models to others. Friendships developed at the center and the opportunity to give help to others were ranked positively but lower. Members assisting each other with self-management was neutral, whereas encouraging members to improve their individual and collective understanding by sharing life experiences was ranked as not important.

In the "Additional Comments" section, three respondents provided 
advice on additional clarifications needed in the survey. Validating the results of the first survey, five respondents stated difficulty in rating the items in that all the criteria were important.

\section{DISCUSSION}

Two different methods were used to identify and prioritize criteria for fidelity to a model of consumer-run services. The criteria were culled from an extensive review of writings of consumers and researchers of consumerism. The fact that in the first wave experts agreed that nearly all the criteria were important, suggests that our review was comprehensive and included the most frequently cited "critical ingredients." The first survey also showed that experts experienced difficulty in assigning different ratings to the criteria. Thus, a forced rating system was used in Wave II to produce priorities. The Wave II priorities should be viewed within the context that all 31 criteria were initially deemed critical to the operations of consumer-run drop-in center programs. The results from Wave II indicate that it is possible to use a modified Delphi process to help experts put priorities on criteria they otherwise deemed to be highly important. The fact that the ratings did not vary by self-identified consumer vs. professional status, nor by years of experience, gives us more confidence in the meaningfulness of the priorities.

\section{Structure vs. Process}

In this project, we found (as have others, e.g., Bond et al., 2000) that experts tend to rate structural (the most visible) components or criteria as "most essential". Criteria from the process domains were given less importance. This is interesting, particularly in the light of some research suggesting that adhering to process criteria may be more significant in maintaining the program model as intended. That is, in studies of Assertive Community Treatment, model drift (from fidelity) occurred less on structural features and more on discretionary (process) features, such as overall treatment approach and in vivo services (Teague et al., 1998).

Structure measures have the advantage of being less subjective and can often be obtained through existing documentation. Process criteria may be more difficult to reliably measure, but more significant in terms of program effects. That is, process criteria include measures of 
program style, staff-client interactions, client-client interactions, individualization of treatment, and emotional climate, which require much more subjective judgments, often based on observations, interviews, etc. Process measures require more time and effort to obtain, and are likely to be more costly and less reliable (Bond et al., 1997). The McGrew et al. (1994) ACT fidelity measure contained 17 items that were readily measured and already available in existing program evaluations; nearly 60 other criteria endorsed by experts were not measured at all. This resulted in a reliable scale, but uneven coverage of program operating characteristics. Lucca's (2000) measure of fidelity to the clubhouse model (2000) used a checklist of only structural service dimensions-no process. A focus on structural criteria may produce high reliability and validity at the cost of overly simplistic conceptions of program operations, while omitting key ingredients which are more complex, reflect values and principles, and may be more significant. (See Herman et al., 2002, report on process measures of the quality of care for schizophrenia.)

\section{Common Underlying Constructs}

The critical ingredients endorsed by respondents as most important were the structural and process components emphasizing the value of consumerism: consumer control, consumer choices and opportunities for decision-making, the voluntary nature of participation (and the absence of coercion), and respect for members by staff. These results reinforce Silverman's comment concerning consumer-run services: "(c)choice is assuredly our most basic and most important value" (Silverman, 1997, p. 132).

Next in importance were program criteria from the "Belief" and "Social Support" domains, providing tentative reinforcement for the schema of empowering settings as outlined by Maton and Salem (1995). The need for programs to promote a recovery orientation and the idea of a strengths-based belief system in which persons are encouraged to take responsibility for recovery and for their health and behavior, were seen as important ingredients for CRDIs. With respect to the social support domain, the results indicate that CRDIs, in their mission statements, need to move beyond the mere provision of support and friendships to create a sense of community (Maton and Salem, 1995). Another interesting aspect of ratings in the social support domain was the relatively low (but still positive) rating given to traditional notions of self-help 
benefits, e.g., giving help to peers and assisting each other in problemsolving.

Components that were seen as least important included outreach, referral, and recruitment activities, regular attendance, skills training, and group empowerment. With the exception of the last item, it may be that these criteria were the least endorsed because they were seen as de facto components of community mental health rather than characteristics exclusive to CRDIs. It might also be that respondents rated these components as lower since the small budgets which typify consumer-run services, are less able to support these activities.

\section{IMPLICATIONS}

Fidelity criteria, typically derived from a research demonstration model or program theory, are increasingly used in sophisticated evaluation practice. The derivation of fidelity criteria is more difficult for emerging models-those not based on theory or empirical research, e.g., grass-roots community programs. The results of this study suggest that fidelity criteria for consumer-run services can be developed from expert consensus and that the most important dimensions of such criteria are choice, opportunities, voluntariness, social support and recovery.

Additional research is needed to operationalize the criteria and to select appropriate tools for their measurement. Data collection and analyses will be needed to determine the extent to which critical ingredients differ across CRDIs, as well as between consumer-run and more traditional mental health or rehabilitation services. The ensuring phase will be of most interest: examining the extent to which consumer ratings of satisfaction, participation, and program benefits relate to the fidelity components. A subsequent line of research would empirically test the relationship between CRDI fidelity to critical ingredients and program effectiveness, in terms of consumer recovery, rehabilitation, and quality of life. The ultimate goal is to determine whether programs operated according to the consumer-run service model make a significant and positive difference in consumer outcomes.

\section{REFERENCES}

Bond, G.R., Drake, R.E., Mueser, K.T., \& Becker, D.R. (1997). An update on supported employment for people with severe mental illness. Psychiatric Services, 48(3), 335-346. 
Bond, G. R., Evans, L., Salyers, M. P., et al. (2000). Measurement of fidelity in psychiatric rehabilitation. Mental Health Services Research, 2(2), 75-87.

Chamberlain, J., Rogers, E. S., \& Ellison, M.L. (1996). Self-help programs: A description of their characteristics and their members. Psychiatric Rehabilitation Journal, 19(3), 33-42.

Clark, C. C., \& Krupa, T. (2002). Reflections on empowerment in community mental health: giving shape to an elusive idea. Psychiatric Rehabilitation Journal, 25(4), 341-349.

Donabedian, A. (1980). Exploration in quality assessment and monitoring: The definition of quality and approaches to assessment. Vol I. Ann Arbor, MI: Health Admin. Press.

Drake, R. E., McHugo, G. J., Becker, D. R., et al. (1996). The New Hampshire study of supported employment for people with severe mental illness. Journal of Consulting and Clinical Psychology, 64(2), 391-399.

Hermann, R. C., Finnerty, M., Provost, S., et al. (2002). Process measures for the assessment and improvement of quality of care for schizophrenia. Schizophrenia Bulletin, 28(1), 95-104.

Le Doux, E. (1997). Revitalizing a consumer-controlled alternative. In Mowbray, C.T., Moxley, D.P., Jasper, C.A. \& Howell, L.L. (Eds.). Consumers as providers in psychiatric rehabilitation (pp. 142-147). Columbia, Md.: International Association of Psychosocial Rehabilitation Services.

Lucca, A.M. (2000). A Clubhouse fidelity index: Preliminary reliability and validity results. Mental Health Services Research, 2(2), 89-94.

Maton, K.I., \& Salem, D.A. (1995). Organizational characteristics of empowering community settings: A multiple case study approach. American Journal of Community Psychology, 23(5), 631-656.

McGrew, J.H., Bond, G.R., Dietaen, L., \& Salyers, M. (1994). Measuring the fidelity of implementation of a mental health program model. Journal of Consulting and Clinical Psychology, $62(4), 670-678$.

McHugo, G. J., Drake, R. E., Teague, G. B., \& Xie, H. (1999). Fidelity to assertive community treatment and client outcomes in the New Hampshire dual disorders study. Psychiatric Services, 50(6), 818-824.

Mead, S., Hilton, D., \& Curtis, L. (2001). Peer support: a theoretical perspective. Psychiatric Rehabilitation Journal, 25(2), 134-141.

Mowbray, C.T., Moxley, D.P., Jasper, C., \& Howell, L. (Eds.). (1997). Consumers as providers in psychiatric rehabilitation. Columbia, Md.: International Association of Psychosocial Rehabilitation Services.

Mowbray, C.T., \& Tan, C. (1992). Evaluation of an innovative consumer-run service model: The Drop-In Center. Innovations \& Research, 1(2), 19-24.

Mueser, K.T., Bond, G.R., Drake, R.E., et al. (1998). Models of community care for severe mental illness: A review of research on case management. Schizophrenia Bulletin, 24, 37-74.

Segal, S. P., \& Silverman, C. (2002). Determinants of client outcomes in self-help agencies. Psychiatric Services, 53(3), 304-309.

Segal, S.P., Silverman, C., \& Temkin, T. (1993). Empowerment and self-help agency practice for people with mental disabilities. Social Work, 38(6), 705-712.

Silverman, S. (1997). Recovery through partnership: "on our own, Charlottesville, Virginia." In Mowbray, C.T., et al., (Eds.). Consumers as providers in psychiatric rehabilitation (pp. 126141). Columbia, Md.: International Assoc. for Psychosocial Rehabilitation Services.

Solomon, P., \& Draine, J. (1996). Perspectives concerning consumers as case managers. Community Mental Health Journal, 32(1), 41-46.

Teague, G.B., Bond, G.R., \& Drake, R.E. (1998). Program fidelity in assertive community treatment: Development and use of a measure. American Journal of Orthopsychiatry, 68(2), 216232.

Teague, G. B., Drake, R. E., \& Ackerson, T. H. (1995). Evaluating use of continuous treatment teams for persons with mental illness and substance abuse. Psychiatric Services, 46 (7), 689695.

Teague, G.B., Ganju, V., Hornik, J.A., et al. (1997). The MHSIP mental health report card. A consumer-oriented approach to monitoring the quality of mental health plans. Evaluation Review, 21 330-341.

Test, M.A. (1998). Community-based treatment models for adults. In Williams, J.B.W. and Ell, K. (Eds.) Advances in mental health research: Implications for practice (pp. 420-436). Silver Springs, MD: NASW Press.

Van Tosh, L., \& del Vecchio, P. (2000). Consumer-operated self-help programs: A technical re- 
port. Center for Mental Services, SAMHSA, PHS, US-DHHS. Rockville, MD (www.samsha. gov).

Yanos, P. T., Primavera, L. H., \& Knight, E. L. (2001). Consumer-run service participation, recovery of social functioning, and the mediating role of psychological factors. Psychiatric Services, $52(4), 493-500$.

Zinman, S. (1986). Self-help: The wave of the future. Hospital and Community Psychiatry, 37(3), 213. 